\title{
Enhanced Membrane Binding of Autoantibodies to Cultured Keratinocytes of Systemic Lupus Erythematosus Patients after Ultraviolet B/Ultraviolet A Irradiation
}

Theo Dov Golan, Keith B. Elkon, Azzudin E. Gharavi, and James G. Krueger *

Department of Medicine, The Hospital for Special Surgery, Cornell University Medical College, New York 10021; and *Laboratory for Investigative Dermatology, The Rockefeller University, New York 10021-6399

\begin{abstract}
Although sunlight is known to induce skin lesions in patients with systemic lupus erythematosus (SLE) and to exacerbate systemic manifestations, the underlying mechanisms remain obscure. We report experiments that show enhanced binding of IgG autoantibodies to the cell surface membrane of ultravioletB ( UVB ) irradiated ( $200-1,600 \mathrm{~J} / \mathrm{m}^{2}$ ) cultured SLE keratinocytes in 10 out of 12 such cell strains. The autoantibody probes showing increased binding were directed against the soluble intracellular antigens, Sm, RNP, SSA / Ro, SSB / La, whereas serum with anti-dsDNA activity did not demonstrate such binding. Control keratinocytes from several sources shared low level binding of autoantibodies after ultraviolet light exposure. In addition, 4/6 UVB-sensitive SLE strains showed increased autoantibody binding to the surface of SLE keratinocytes after UVA exposure (50-150 $\left.\mathrm{kJ} / \mathrm{m}^{2}\right)$, but of lower magnitude. When UVB-sensitive nonirradiated SLE strains were exposed to autologous serum, 3 /8 sera demonstrated a striking increase in IgG binding, which increased further after UVB exposure. Enhanced expression of saline-soluble intracellular antigens on the cell surface membrane of patient, but not control, keratinocytes may, in part, explain the photosensitivity of patients with SLE. ( J. Clin. Invest. 1992.90:1067-1076.) Key words: ultraviolet light • systemic lupus erythematosus • keratinocytes • autoantigens
\end{abstract}

\section{Introduction}

Photosensitivity is one of the most frequent symptoms of systemic lupus erythematosus (SLE) ${ }^{1}(1)$. Exposure to solar radiation is known to induce skin lesions and may also exacerbate systemic disease activity (2). Although cutaneous lesions in sun-sensitive patients have been elicited by ultraviolet radiation (UVR) under controlled experimental conditions $(3,4)$,

Address correspondence to Theo Dov Golan, M. D., Clinical Immunology, Bnai Zion Medical Center, and Department of Immunology, Faculty of Medicine, Technion, P. O. Box 4940, Haifa, Israel 31048, which is his permanent address. 1992

Received for publication 9 July 1991 and in revised form 23 March

1. Abbreviations used in this paper: $\mathrm{AO}$, acridine orange; $\mathrm{CIE}$, counterimmunoelectrophoresis; EB, ethidium bromide; IIF, indirect immunofluorescence; SCA, soluble cellular antigens; SLE, systemic lupus erythematosus; TB, trypan blue; UVR, ultraviolet radiation.

J. Clin. Invest.

(c) The American Society for Clinical Investigation, Inc.

$0021-9738 / 92 / 09 / 1067 / 10 \quad \$ 2.00$

Volume 90, September 1992, 1067-1076 the exact mechanisms are not fully understood (5). In SLE patients, immunoreactants are mainly deposited at the dermoepidermal junction of sun-exposed skin (6). Similar immune deposits can be induced experimentally by UVC (200-290 $\mathrm{nm}$ ), presumably as a result of the local release of ultraviolet-altered DNA (UV-DNA) and binding by specific autoantibodies in the skin $(7,8)$. However, it has become apparent that UVCaltered DNA is of little clinical relevance in inducing SLE in vivo (9) and that solar UV reaching the surface of the earth is mainly composed of UVA (320-400 nm) (90-95\%) and UVB (290-320 nm), with little or no penetration of UVC through the stratospheric ozone layer (10).

Recent studies have shown that UV-induced DNA damage varies according to the nature of the UV source used and that alterations in cellular macromolecules other than DNA may be induced by UVA and UVB irradiation. UVA and UVB may affect both RNA and protein synthesis and cell membrane permeability $(11,12)$. In this regard, the finding that UVB irradiation of normal human keratinocytes induced autoantibody binding to soluble cellular antigens (SCA), such as SSA(Ro) and $\operatorname{SSB}(\mathrm{La})$, on the surface of human keratinocytes is of importance $(13,14)$. The presence of these antibodies in the sera of SLE patients is known to be associated with photosensitivity, especially in patients with the subacute cutaneous LE variant $(15)$.

We have recently demonstrated an enhanced sensitivity of dermal fibroblasts and peripheral blood lymphocytes derived from SLE patients to UVB irradiation in vitro (16). Since the epidermal keratinocyte is the major target of immunologic damage in photosensitive SLE patients (14), the effect of UV irradiation on SLE-derived keratinocytes was studied in vitro. Our data showed that SLE-derived keratinocytes were more susceptible than control keratinocytes to UV-induced intracellular and cell surface expression of soluble intracellular antigens.

\section{Methods}

Patients and controls. 12 SLE patients ( 11 females and 1 male, aged 24-63 yr), who fulfilled four or more of the American Rheumatism Association revised criteria for the classification of SLE (1), two female patients with facial basal cell carcinoma (aged 61-78 yr), and four female patients with RA (aged 51-60 yr) were included in this study, after giving informed consent. All patients were attending the outpatient clinic and were either in clinical remission or had mild clinical activity. Cells cultured from 13 healthy individuals ( 9 male neonates and 4 adult females, aged 49-56 yr) were included as controls. Sera from all patients were obtained and tested for the presence of autoantibodies as described below.

Keratinocyte cell cultures. Skin specimens were obtained from the inner forearm of each patient by a modified suction blister machine (designed and built by the Laboratory for Investigative Dermatology, 
The Rockefeller University) as described elsewhere (17). The donor sites were warmed to $37^{\circ} \mathrm{C}$ by an electronic controlled heating device and were kept under negative pressure of $350-420 \mathrm{mmHg}$. Within 45-60 min blisters were raised (usually two) of $5 \mathrm{~mm}$ in diameter. The roofs of these blisters were removed under sterile conditions with fine surgical scissors, rinsed separately in PBS containing antibiotics, and then incubated in $0.25 \%$ trypsin in EDTA $0.342 \mathrm{~mol} /$ liter (Clonetics Corp., San Diego, CA ). After 20 min incubation at $37^{\circ} \mathrm{C}$, gentle agitation, and centrifugation, the cell pellets were harvested. Surgical skin specimens obtained from controls (foreskins from circumcised neonates and facial skin from cosmetic facial procedures) were incubated overnight in Dispase (1\%, neutral protease derived from Bacillus polymyxa, grade II, Cell Biology; Boehringer Mannheim GmbH, Mannheim, Germany), to produce epidermal separation, thereafter epidermal sheets were treated identically to suction blister samples. After resuspension of cell pellets, keratinocytes were plated into sterile 75$\mathrm{cm}^{2}$ plastic flasks (Falcon Labware, Becton, Dickinson, \& Co., Lincoln Park, NJ) and grown in serum-free defined medium (KGM; Clonetics Corp.) at $37^{\circ} \mathrm{C}$ in a humid gaseous mixture of $75 \% \mathrm{~N}_{2}, 5 \% \mathrm{CO}_{2}, 20 \%$ $\mathrm{O}_{2}$. Primary cultures were further expanded in two passages. In the second passage, cells $\left(7.5 \times 10^{4}\right.$ cells $/ 3 \mathrm{ml}$ per well $)$ were distributed into sterile six-well plates containing glass cover slips and were maintained in culture for 3-4 d before experimental use. Under these conditions nonconfluent, discrete, nonstratifying monolayer colonies of 2050 cells were formed ( mean cell viability $97.2 \pm 1.2 \%$ ). Excess cells from the second passage were frozen in aliquots and used in repeated experiments.

UV irradiation. Before irradiation, cell culture medium was replaced by PBS to avoid any toxic photochemical effects of UVR on cell growth. At least one specimen of keratinocytes (grown on glass slides) of each cell strain (in duplicate) was not exposed to UVR (but was handled otherwise in the same way as irradiated cells), whereas the remainder of the cells was exposed separately to various doses of UVR as detailed in Results. A sun lamp battery (FS 20; Westinghouse Electric Corp., Pittsburgh, PA) housed in a reflector unit was used as a UVB light source. The irradiance of this unit, as measured by a radiometer (IL 1700 [photodetector SED 240]; International Light, Inc., Newburyport, MA), was $0.5 \mathrm{~mW} / \mathrm{cm}^{2}$ at a distance of $15 \mathrm{~cm}$ and contained $24 \%$ of UVA emission. A Black Light (F587T12-BL-HO; Derma Control, Frankfort, IL) battery housed in a reflector unit was used as a UVA light source. The irradiance of this unit as measured by a radiometer (IL 1700 [photodetector SED 038]; International Light, Inc.) was $12.0 \mathrm{~mW} / \mathrm{cm}^{2}$ at a distance of $15 \mathrm{~cm}$ and contained $<0.3 \%$ UVB emission. A Schott filter (WG-335, 2-mm thickness; Glass Technologies Inc., Duryea, PA) placed during irradiation between UVA source and cultured cells (and under controlled temperature not exceeding $30^{\circ} \mathrm{C}$ ) reduced UVA emission to $9.4 \mathrm{~mW} / \mathrm{cm}^{2}$ and practically eliminated UVB irradiance $(<0.015 \%)$. After irradiation cells were immediately reconstituted with fresh medium and cultures were usually further incubated for $20 \mathrm{~h}$. At this stage ( 0 hour) viability of cultures was assessed by the trypan blue (TB) dye exclusion test.

Autoantibody detection and selection of antibody probes. Autoantibodies to the SCA (SSA/Ro, SSB/La, Sm, RNP) were determined by counterimmunoelectrophoresis (CIE) as described previously (18). Autoantibody probes used in this study for the analysis of the expression of the SCA on keratinocytes were selected from sera studied in detail previously $(18,19)$. The anti-SSA/SSB serum was obtained from a patient with primary Sjögren's syndrom and did not bind to other proteins on immunoblots or to DNA. The anti-Sm serum obtained from a patient with SLE showed weak anti-RNP activity by CIE, whereas the anti-RNP antibody (obtained from a patient with mixed connective tissue disease) was apparently monospecific. The antidsDNA antibody was negative by CIE and did not bind to protein antigens on immunoblots. In a few experiments one additional antiserum was used: a rabbit antiglucoronic transferase (gift of Dr. Andrew Dannenberg, New York Hospital-Cornell Medical Center, New York).

Indirect immunofluorescent (IIF) staining of living cells. Thirdpassage keratinocytes (maintained in culture on glass slides) were washed with cold $\left(4^{\circ} \mathrm{C}\right) \mathrm{PBS}$ and then incubated with diluted test sera $(1: 50)$ at $2^{\circ} \mathrm{C}$ (to prevent endocytosis) for $1 \mathrm{~h}$. Thereafter cells were washed twice for $10 \mathrm{~min}$ in cold PBS, followed by immersion of slides into a TB solution ( $0.1 \%$; Gibco Laboratories, Grand Island, NY) at $4^{\circ} \mathrm{C}$ for $45 \mathrm{~s}$ and then immediately immersed in cold acetone $\left(4^{\circ} \mathrm{C}\right.$ for 2 $\mathrm{min}$ ). After a further wash, the slides were incubated with fluoresceinated goat anti-human IgG ( 1:50 dilution; Tago Inc., Burlingame, CA) for $30 \mathrm{~min}$ at room temperature and were then mounted in a glycerol/ paraphenylenediamine solution (13). Simultaneous microscopic inspection of stained slides under bright or UV light ( fluorescence microscope, model 250; Ernst Leitz GmbH, Wetzlar, Germany) was performed by two investigators independently (TDG and AEG). At least 300 cells that excluded the TB dye (TB negative) were inspected in each specimen and the number of cells with membrane staining was determined. In many experiments two cell lines were tested in parallel: one normal and one SLE-derived cell line.

Cell viability. The TB dye exclusion test was used in all experiments to assess the viability of cell cultures before the start of staining procedures (viability I) and again immediately before cell fixation of living cells ( viability II). However, in some experiments cell viability of UVirradiated and nonirradiated cultures was measured by ethidium bromide (EB) with acridine orange (AO) (20). The results with EB/AO staining in which, under UV light illumination, nonviable cells stain orange-red and viable cells show bright green stain, were similar to those obtained by TB exclusion test. Since acetone fixation removes $\mathrm{EB} / \mathrm{AO}$ stain, this viability staining was omitted in further experiments. In addition, simultaneous examination of individual cells by bright and immunofluorescence microscopy provided assurance that cells with positive immunofluorescence but negative TB staining continued to be viable through the steps of the IIF staining procedure up to that of acetone fixation. The mean percentage of viable cells was determined by counting at least 200 cells (TB negative or positive) in three different microscopic fields of each specimen.

Statistical analysis. Repeated measures by analysis of variance were performed to detect differences between autoantibody probes and cell strains across various levels of irradiation. Multiple comparisons by paired and independent $t$ tests with a Bonferroni correction (alpha was set at 0.05 ) were used to detect differences among subgroups of probes, at various points of reference. Probabilities of $<0.005$ were accepted as statistically significant. Since this is a conservative correction, it may underestimate real differences.

\section{Results}

Clinical and serological evaluation. Table I summarizes the patients' age, gender, duration of disease, organ involvement, autoantibody profile, and treatment at entry to study. 6 patients $(50 \%)$ had a history of sun sensitivity and 10 patients $(83 \%)$ had a history of skin lesions. None had subacute cutaneous LE. Involvement of other organs are shown in Table I. The serological profile of the 12 patients revealed that all patients (100\%) were ANA positive. Other autoantibodies detected were: anti-dsDNA in seven (58\%), anti-Sm in three $(25 \%)$, anti-nRNP in six (50\%), anti-SSA in five $(42 \%)$, and anti-SSB in one patient (8\%). Two patients received no maintenance therapy at the time of study. One patient received dihydroxychloroquine sulfate, one patient received this drug in combination with prednisolone, one patient received nonsteroidal antiinflammatory drugs, and the remaining seven (58\%) were on 5-40 mg prednisolone daily. None of these patients were on other immunosuppressive therapy. The duration of disease activity in the four RA patients ranged from 7 to $15 \mathrm{yr}$. Three out of four patients with RA had disabling joint deformities and one had bilateral joint replacements of both knees. Three patients were on nonsteroidal antiinflammatory drug mainte- 


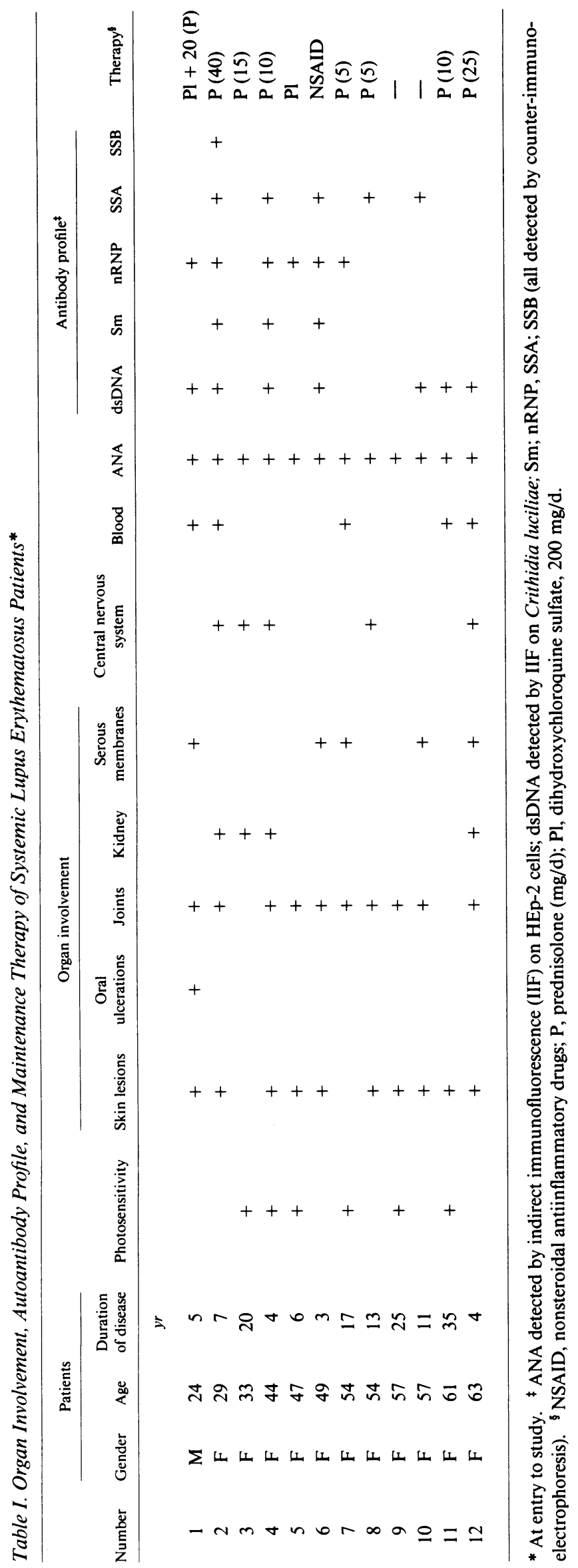

nance therapy, and one also received $20 \mathrm{mg}$ prednisolone daily. Two RA patients were ANA positive and also had high titers of rheumatoid factor. The two patients with basal cell carcinomas had no history of photosensitivity or any other pertinent physical or serological abnormalities.

Baseline data for the binding of autoantibody probes to cellular antigens on the cell surface of nonirradiated and UV-irradiated normal keratinocytes in vitro. First, to confirm previous reports $(13,14)$ we examined the binding of different autoantibody probes to the membrane of non-UV irradiated cells derived from healthy individuals as an indication of cell-surface antigen expression in vitro. Direct and simultaneous microscopic examination of cells by bright and immunofluorescent light allowed the discrimination at the single-cell level between those which were nonviable before fixation (TB-positive) and those which were viable up to that step (and therefore TB-negative). As shown in Table II, the rarity of IIF-positive staining cells among all TB-negative ones in nonirradiated keratinocytes derived from either neonatal or adult sources was demonstrated and the percentage $(0.3-4.1 \%)$ varied according to the autoantibody probe used. Cultures of either neonatal or adult origin showed a similar percentage of viability $(97.8 \pm 1.5$ and $97.2 \pm 1.2 \%$, respectively) and maintained high viability up to the step of cell fixation $(92.3 \pm 1.2$ and $93.0 \pm 1.4 \%$, respectively). To verify that the additional step of TB staining (before cell fixation ) did not affect IIF staining, experiments were conducted in which this step was omitted. No difference in the percentage of membrane IIF-positive cells was observed.

Another series of experiments was performed in which keratinocytes derived from normal controls were exposed to increasing doses of UVB irradiation $\left(0-2500 \mathrm{~J} / \mathrm{m}^{2}\right)$ and the effect on cell surface expression of cellular antigens $20 \mathrm{~h}$ after exposure was studied. This time interval was chosen after initial experiments (in which IIF staining was performed at 4, 8, 16,20 , and $24 \mathrm{~h}$ after irradiation ) revealed that the 20 -h postirradiation interval was the most effective in demonstrating changes in cell membrane expression of these presumably translocated antigens. The cumulative data of these experiments showed ( Table III) a doubling of the mean percentage of positive-staining cells ( the highest was $8.2 \pm 0.3 \%$ for anti-SSA/ SSB probe) in keratinocytes exposed to $1,600-2,500 \mathrm{~J} / \mathrm{m}^{2}$ UVB. The approximately twofold increase was also observed with all of the other autoantibody probes used, except antidsDNA, which remained similar to that of nonirradiated cells $(0.2 \pm 0.1 \%)$. In addition, no significant differences were observed among neonatal and adult cells at any given dose of UVB exposure for any of the probes used. The mean viability immediately before fixation (viability II) of normal nonirradiated keratinocytes was $93.3 \pm 1.7 \%$ and that of irradiated keratinocytes ( $20 \mathrm{~h}$ after UVB exposure) varied according to intensity of radiation, but was equal in both cell sources for any given dose. For example, a dose of $800 \mathrm{~J} / \mathrm{m}^{2}$ resulted in $10 \%$ cell death whereas $1,600 \mathrm{~J} / \mathrm{m}^{2}$ produced $15-20 \%$ cell death and exposure to $2,500 \mathrm{~J} / \mathrm{m}^{2}$ resulted in viability ranging from 65 to $75 \%$. Consequently, in the following experiments, UVB irradiation of cultured keratinocytes derived from normal (neonate or adult) or SLE sources did not exceed 1,600 J/ $\mathrm{m}^{2}$ and the cells were examined $20 \mathrm{~h}$ after UV exposure.

To evaluate possible synergy between UVB and UVA contained in the UVB source (for example, a dose of $96 \mathrm{~J} / \mathrm{m}^{2}$ UVA is contained in a $400 \mathrm{~J} / \mathrm{m}^{2} \mathrm{UVB}$ irradiation), and since no monochromatic light sources were used, cultured normal 
Table II. Percentage of Positive Cell Surface Staining in Nonirradiated Normal Keratinocytes Derived from Neonates or Adults In Vitro

\begin{tabular}{lcccc}
\hline \multirow{2}{*}{ Cell source } & \multicolumn{4}{c}{ Autoantibody probe* } \\
\cline { 2 - 5 } & dsDNA & Sm & nRNP & SSA/SSB \\
\hline Neonates $(n=9)$ & $0.3 \pm 0.1$ & $1.3 \pm 0.3$ & $3.1 \pm 0.4$ & $3.8 \pm 0.4$ \\
Adults $(n=4)$ & $0.3 \pm 0.1$ & $1.4 \pm 0.2$ & $3.6 \pm 0.4$ & $4.1 \pm 0.2$
\end{tabular}

* The results represent the mean percentage \pm SD obtained with any given probe in each cell source. Significant differences exist among all probes $(P<0.001)$. No significant difference was observed when results of neonatal cells were compared with those of adults $(P>0.1)$.

keratinocytes were simultaneously irradiated by the two UV sources delivering $1,600 \mathrm{~J} / \mathrm{m}^{2} \mathrm{UVB}$ and $10,000 \mathrm{~J} / \mathrm{m}^{2} \mathrm{UVA}(25$ times the UVA irradiation contained in the UVB source). $20 \mathrm{~h}$ thereafter, cells were examined for autoantibody binding and cell viability. The results of these experiments did not differ from those obtained by UVB irradiation alone (data not shown). Furthermore, exposure of the normal keratinocytes to UVA light at doses of $50-200 \mathrm{~kJ} / \mathrm{m}^{2}$ had no effect on cell viability or autoantibody binding.

Binding of autoantibody probes to UV-irradiated SLE-derived keratinocytes in vitro. Fig. 1 displays patterns of autoantibody binding to lupus-derived keratinocytes incubated with antibody before or after fixation/permeabilization with acetone. Discrete, focal cell surface staining is detected in some keratinocytes with SSA/SSB autoantibodies (Fig. $1 A$ ). The cell surface pattern is clearly distinguishable from the typical nuclear/cytoplasmic SSA/SSB pattern obtained on cells fixed and permeabilized before reaction with antibodies (Fig. $1 B$ ). Similarly, reaction of unfixed keratinocytes with anti-Sm antibodies produced granular and punctate cell surface staining (Fig. $1 C$ ) that was clearly distinguishable from reaction of these antibodies with fixed keratinocytes (Fig. $1 D$ ). The cytoplasmic/nuclear IIF staining pattern of TB-positive cells was similar to that of prefixed cells, depending on the autoantibody probe used, but did not show cell membrane binding. In contrast, a small proportion $(<10 \%)$ of TB-negative cells that showed cell surface binding of SCA autoantibody probes also showed cytoplasmic and nuclear staining as illustrated in Fig. $1 C$.

To determine whether SLE-derived keratinocytes were more susceptible to UV irradiation, SLE-derived keratinocytes were exposed to increasing doses of UVB irradiation and binding of autoantibody probes to unfixed cells was assessed. As shown in Fig. 2, $A-C, 10$ of 12 SLE-derived cell strains showed a significantly increased expression of soluble nuclear antigens on the cell surface membrane compared with normal cell strains. All of the $10 \mathrm{UV}$-sensitive SLE strains demonstrated a dose-dependent sensitivity to irradiation, although augmented expression differed among individual strains. The dose-related increase in percentage of positive-staining cells ( compared with their own nonirradiated specimens) was evident in all SLE cell strains exposed to $\geq 400 \mathrm{~J} / \mathrm{m}^{2}$. The increased detection of the different cellular soluble antigens varied, but the mean percentage of Sm-positive cells was the highest at any given UV dose in comparison to other probes (Fig. 2). It is interesting that UV exposure increases extracellular expression of saline-extractable nuclear antigens. Since these antigens are readily extracted by neutral saline buffers, they may have the ability to diffuse from their usual cellular location(s) to the extracellular compartment after UV-induced membrane/cellular damage. In support of this concept, one fixed cellular antigen (dsDNA) would not be capable of diffusion and its expression on the cell surface is not increased by UV exposure (Table III). In a small number of cases, we also measured cell surface expression of protein anchored to endoplasmic reticulum membranes (glucoronic transferase) after UV exposure. No cell surface expression was detected at any UV dose used, although internal membrane staining was readily detected after detergent per-

Table III. Autoantibody Binding to the Cell Surface of Normal Keratinocytes after Ultraviolet B Irradiation In Vitro*

\begin{tabular}{|c|c|c|c|c|c|c|}
\hline \multirow{2}{*}{$\begin{array}{l}\text { Cell } \\
\text { source }\end{array}$} & \multirow{2}{*}{$\begin{array}{l}\text { Antibody } \\
\text { probe }\end{array}$} & \multicolumn{5}{|c|}{ UVB irradiation } \\
\hline & & 200 & 400 & 800 & 1600 & 2500 \\
\hline & & \multicolumn{5}{|c|}{$\mathrm{J} / \mathrm{m}^{2}$} \\
\hline \multicolumn{7}{|l|}{ Neonates } \\
\hline \multirow[t]{5}{*}{$(n=6)$} & SSA/SSB & $3.8 \pm 0.4$ & $4.0 \pm 0.3$ & $4.4 \pm 0.4$ & $7.2 \pm 0.1^{\ddagger}$ & $8.0 \pm 0.2^{\ddagger}$ \\
\hline & nRNP & $3.1 \pm 0.4$ & $3.1 \pm 0.1$ & $4.2 \pm 0.3$ & $5.8 \pm 0.3^{\ddagger}$ & $7.8 \pm 0.1^{\ddagger}$ \\
\hline & $\mathrm{Sm}$ & $1.2 \pm 0.3$ & $2.9 \pm 0.1$ & $3.0 \pm 0.1$ & $3.6 \pm 0.4^{\ddagger}$ & $4.1 \pm 0.1^{\ddagger}$ \\
\hline & dsDNA & $0.2 \pm 0.1$ & $0.2 \pm 0.1$ & $0.2 \pm 0.1$ & $0.2 \pm 0.1$ & $0.2 \pm 0.1$ \\
\hline & NHS & 0 & n.d. & n.d. & n.d. & 0 \\
\hline \multicolumn{7}{|l|}{ Adults } \\
\hline \multirow[t]{5}{*}{$(n=4)$} & SSA/SSB & $3.6 \pm 0.7$ & $4.2 \pm 0.1$ & $4.3 \pm 0.4$ & $7.6 \pm 0.6^{\ddagger}$ & $8.2 \pm 0.3^{\ddagger}$ \\
\hline & nRNP & $2.6 \pm 0.4$ & $3.4 \pm 0.3$ & $4.0 \pm 0.3$ & $5.9 \pm 0.7^{\ddagger}$ & $7.2 \pm 0.1^{\ddagger}$ \\
\hline & $\mathrm{Sm}$ & $2.2 \pm 0.1$ & $2.8 \pm 0.3$ & $2.8 \pm 0.1$ & $3.9 \pm 0.3^{\ddagger}$ & $4.0 \pm 0.3^{\ddagger}$ \\
\hline & dsDNA & $0.2 \pm 0.1$ & $0.2 \pm 0.1$ & $0.3 \pm 0.1$ & $0.2 \pm 0.1$ & $0.2 \pm 0.1$ \\
\hline & NHS & 0 & n.d. & n.d. & n.d. & 0 \\
\hline
\end{tabular}

No significant difference $(P>0.1)$ is observed when results of each probe are compared with those of neonates at any given dose of irradiation. ${ }^{*}$ Results represent mean percentage $( \pm \mathrm{SD})$ of IIF-positive cells (in duplicate) $20 \mathrm{~h}$ after irradiation. ${ }^{\ddagger} \mathrm{A}$ significant difference exists $(P<0.001)$ when results are compared with those obtained in nonirradiated specimens (Table II). 

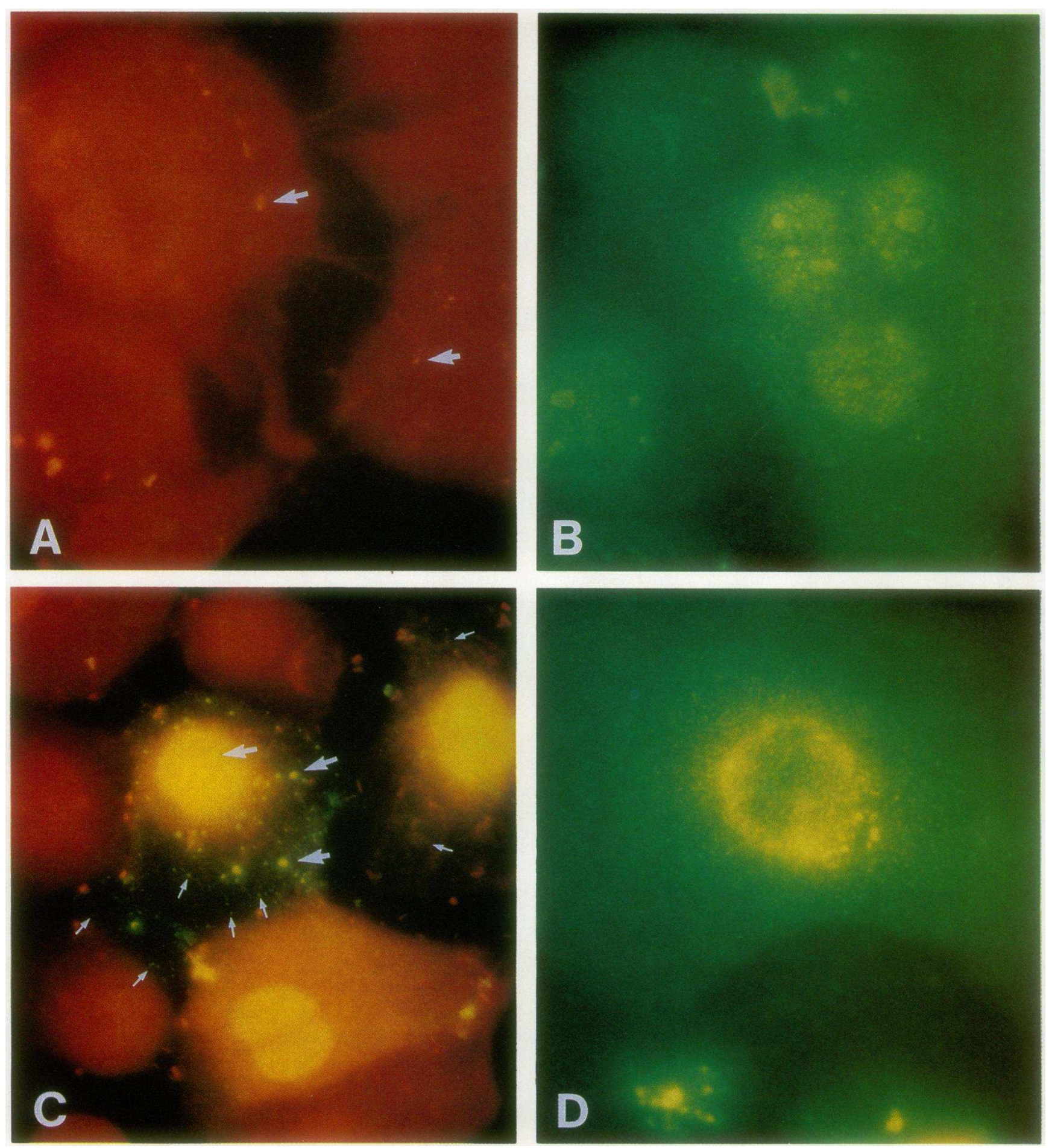

Figure 1. IIF staining of SLE-derived keratinocytes with autoantibody probes. Cells were cultured on glass slides for 3-4 d before IIF staining. Magnification, 630. ( $A$ ) IIF staining pattern of cells fixed and permeabilized after the addition of the primary antiserum (anti-SSA/SSB) and $20 \mathrm{~h}$ after UVB irradiation $\left(200 \mathrm{~J} / \mathrm{m}^{2}\right.$ ). Note fine punctate or granular (green-yellow) IIF staining in cells (arrows). The mounting solution glycerol/PPD accounts for the brick-red counterstain. (B) IIF staining pattern by the same antibody probe of cells fixed and permeabilized before application of the primary antibody. Note the absence of membrane staining in the presence of green nuclear and cytoplasmic fluorescence. $(C)$ IIF staining pattern obtained by an anti-Sm antibody applied to cells before fixation (found occasionally in nonirradiated cells). Note punctuate (green, small arrows) membrane and granular (green-yellow) cytoplasmic and nuclear fluorescence of varying intensity (large arrows). (D) IIF staining pattern of prefixed cells by anti-Sm, devoid of membrane fluorescence. 

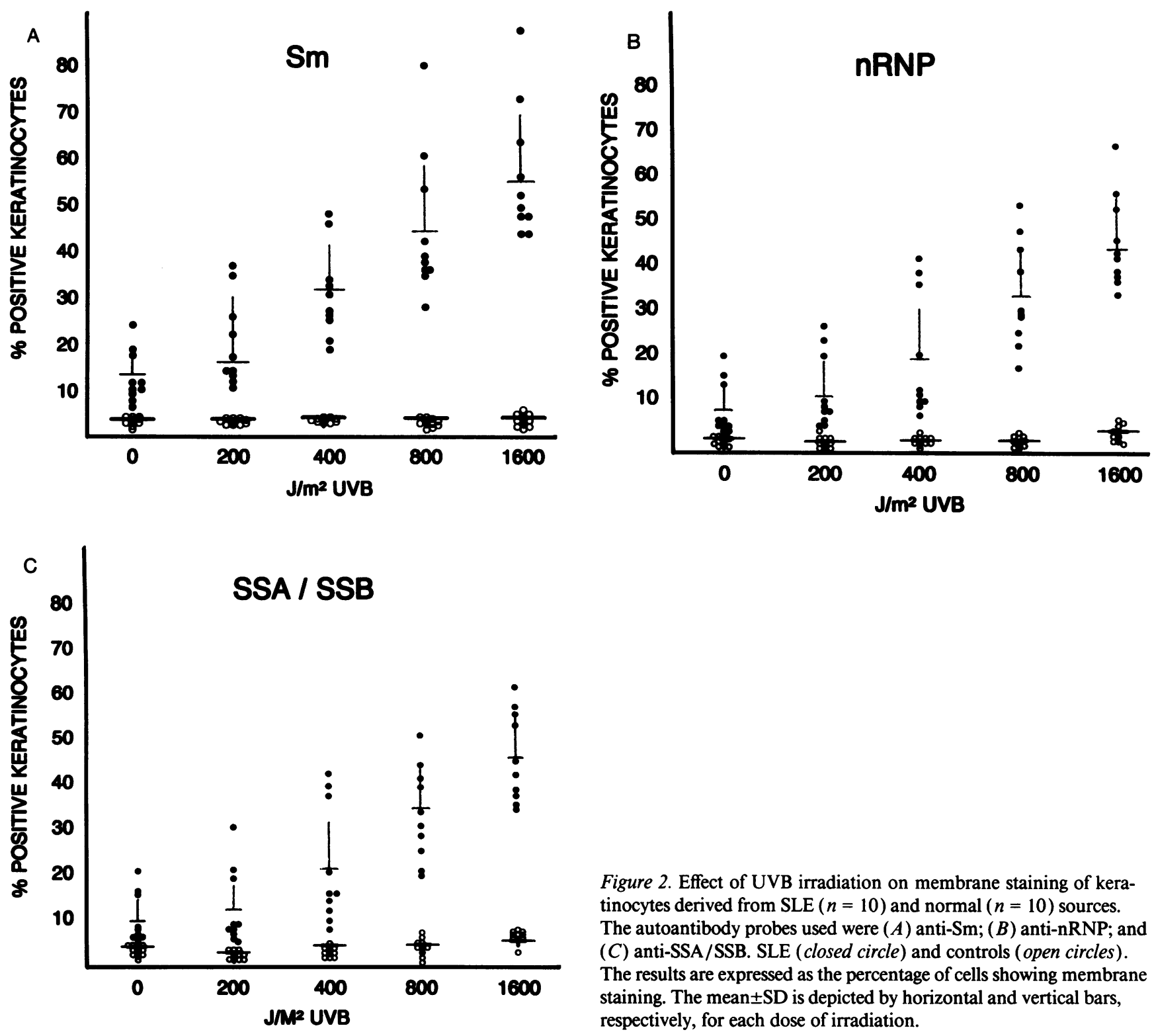

Figure 2. Effect of UVB irradiation on membrane staining of keratinocytes derived from SLE $(n=10)$ and normal $(n=10)$ sources. The autoantibody probes used were $(A)$ anti-Sm; $(B)$ anti-nRNP; and (C) anti-SSA/SSB. SLE (closed circle) and controls (open circles). The results are expressed as the percentage of cells showing membrane staining. The mean $\pm \mathrm{SD}$ is depicted by horizontal and vertical bars, respectively, for each dose of irradiation.

meabilization of cell (data not shown). No difference in results of IIF staining was demonstrated when SLE-derived cells were simultaneously exposed to a mixture of UV light delivered by the two UV sources $\left(200 \mathrm{~J} / \mathrm{m}^{2} \mathrm{UVB}\right.$ and $\left.1,500 \mathrm{~J} / \mathrm{m}^{2} \mathrm{UVA}\right)$ compared with those observed when cells exposed to the UVB source alone (data not shown). When six UV-sensitive SLE strains (Table I, patients No. 1, 5-7, 9, 11) were exposed to UVA irradiation ranging from 50 to $150 \mathrm{~kJ} / \mathrm{m}^{2}$, four (patients No. 5-7, 9) showed a two- to threefold increase in percentage IIF-positive membrane staining at $\geq 100 \mathrm{~kJ} / \mathrm{m}^{2}$, not paralleled by decrease in cell viability. In addition, an increase in the intensity of cytoplasmic or nuclear staining was observed in many of the SLE-derived cell strains after UV irradiation (both in TB-positive and in TB-negative cells) compared with nonirradiated IIF-positive cells.

Normal cell strains usually did not show such sensitivity and remained unaffected by UVB irradiation $<1,600 \mathrm{~J} / \mathrm{m}^{2}$ (Fig. 2 and Table III). At $1,600 \mathrm{~J} / \mathrm{m}^{2}$, a $1.5-2$-fold increase in probes (except anti-dsDNA) compared with their own unexposed specimens. The mean percentage of anti-SSA/SSB staining (but not anti-Sm) was greater at any given UVB dose compared with other probes used (Fig. 2 and Table III). In contrast, when equivalent experiments were conducted in four RA-derived and two basal cell carcinoma-derived keratinocyte strains no statistically significant increase in the presence of translocated cellular antigens on the cell surface after UVB or UVA exposure was observed (data not shown).

Effect of UVB irradiation on cell viability of keratinocytes derived from $S L E$ patients and normal controls. The lethal changes (observed by microscopy) induced by UVR are evidenced by cell degeneration, cell detachment from glass cover slip, and eventual loss from the culture. The cumulative results of experiments performed in 12 SLE-derived cell strains and 13 normals are demonstrated in Fig. 3. The data show diminution of cell viability in SLE cells after being exposed to $200 \mathrm{~J} / \mathrm{m}^{2}$ UVB (compared with unexposed specimens) and that the percentage viability was dose-dependent (mean $43.8 \pm 2.7 \%$ alive 


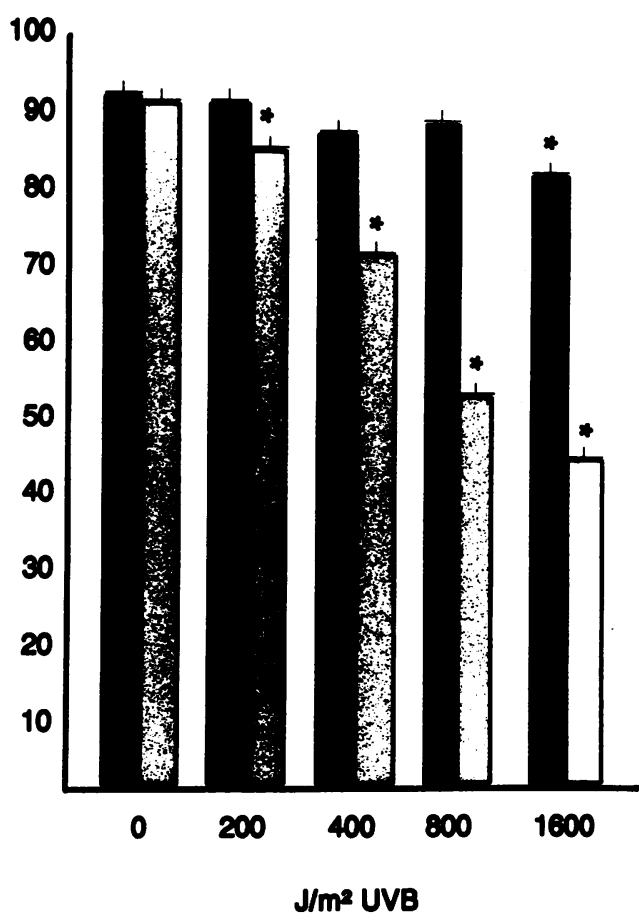

Figure 3. Effect of UVB irradiation on cell viability. Mean viability (percentage $\pm \mathrm{SD}$ ) of nonirradiated or UVB-irradiated keratinocytes was assessed by TB exclusion. (Normals [black box], SLE [shaded box]). The asterisks denote $P<0.001$ when results of SLE strains are compared with those of normals at any given UVB dose or to SLE-derived but UVB-unexposed specimens. In contrast, only the viability of normal strains exposed to $1,600 \mathrm{~J} / \mathrm{m}^{2} \mathrm{UVB}$ is significantly decreased compared with that of normal UVB unexposed cells $(P$ $<0.001$ ).

at $\left.1,600 \mathrm{~J} / \mathrm{m}^{2}\right)$. In contrast, cells derived from normal controls were relatively unaffected $\leq 800 \mathrm{~J} / \mathrm{m}^{2}$ UVB. At $1,600 \mathrm{~J} / \mathrm{m}^{2}$ a decrease in viability (mean $82.7 \pm 1.8 \%$ viable) was statistically significant compared with unirradiated cultures.

Binding of autologous serum of SLE patients to self-derived keratinocytes in vitro. Since sufficient autologous serum was available from eight SLE patients, we determined whether autologous antibodies would bind to irradiated keratinocytes in a manner similar to heterologous autoantibodies. Table IV and Fig. 4 show the results of an experiment in which such a comparative examination was performed on patient No. 10 (Table I). The data show in both nonirradiated and irradiated cells a high percentage of positive staining by autologous serum to self-derived cells. Similar results were obtained in two additional SLE cell strains (Table I, patients No. 7 and 9) but not in the remaining five patients' strains (No. 1, 4-6, 11). In some SLE cell strains the enhanced extracellular expression of these antigens was observed without exposure of cells to direct UV light (Fig. 4, Table IV).

Correlation between $U V$-induced cell surface expression of soluble cellular antigens and clinical features. To quantitate the degree of UVB sensitivity, SLE-derived strains were divided into three groups based upon percentage of positive-staining cells: group 1: high, Nos. 7, 9, 10; group 2: low, Nos. 1, 4-6, 8, 11, 12; and group 3: negative, Nos. 2, 3 (patient numbers refer to Table I). Group 1 demonstrated a four- to fivefold increase in the percentage (above baseline levels of normal strains) of positive-staining cells compared with unirradiated specimens. This group expressed the highest results of the total series of autoantibody binding at any given UVB dose and also demonstrated a high percentage of binding both in unirradiated and irradiated specimens after incubation with autologous serum (Figs. 1 and 4 and Table IV). In contrast, results comparable to normal strains were obtained in group 3 at all points of reference (data not shown). Group 2 demonstrated stainings similar to that of normal strains in nonirradiated specimens whereas staining was significantly higher than controls in all UVB-irradiated cultures. Any correlation between degree of UVB sensitivity (by groups) and sun sensitivity, skin manifestations, or SSA/SSB positivity of sera or maintenance therapy was not observed.

\section{Discussion}

The finding of enhanced UVB-induced binding of autoantibodies to SCA on the cell surface of normal keratinocytes in vitro $(13,14)$ raised the possibility that UV-inflicted cell damage may induce cell surface expression of these presumably translocated antigens. Since defective DNA repair in cells obtained from patients with SLE after UVB (16) or UVC (21-23) irra-

Table IV. Binding of Autologous Serum from a Systemic Lupus Erythematosus Patient* to the Cell Membrane of Autologous Keratinocytes and Normal Control in Comparison to that of Heterologous Probes to Same Cell Sources In Vitro

\begin{tabular}{|c|c|c|c|c|c|c|c|c|c|c|}
\hline \multirow[b]{3}{*}{ Antibody probe } & \multicolumn{10}{|c|}{ UBV irradiation } \\
\hline & \multicolumn{2}{|c|}{0} & \multicolumn{2}{|c|}{200} & \multicolumn{2}{|c|}{400} & \multicolumn{2}{|c|}{800} & \multicolumn{2}{|c|}{1,600} \\
\hline & SLE & Control & SLE & Control & SLE & Control & SLE & Control & SLE & Control \\
\hline & \multicolumn{10}{|c|}{$\mathrm{J} / \mathrm{m}^{2}$} \\
\hline SSA/SSB & $8.2 \pm 0.6$ & $3.1 \pm 0.1$ & $8.8 \pm 0.6$ & $3.3 \pm 0.1$ & $9.2 \pm 1.0$ & $3.0 \pm 0.1$ & $21.2 \pm 4.2$ & $3.1 \pm 0.4$ & $35.3 \pm 1.4$ & $3.9 \pm 0.1$ \\
\hline Sm & $16.4 \pm 0.7$ & $1.2 \pm 0.3$ & $31.2 \pm 2.5$ & $2.8 \pm 0.1$ & $34.3 \pm 3.1$ & $2.6 \pm 0.5$ & $37.8 \pm 2.4$ & $1.7 \pm 0.1$ & $50.5 \pm 2.1$ & $2.2 \pm 0.3$ \\
\hline Autologous serum & $48.6 \pm 0.9$ & $3.4 \pm 0.2$ & $76.0 \pm 4.9$ & $4.6 \pm 0.3$ & $80.5 \pm 3.5$ & $4.8 \pm 0.3$ & $82.1 \pm 5.5$ & $4.7 \pm 0.3$ & $84.6 \pm 2.0$ & $5.0 \pm 0.1$ \\
\hline Cell viability ${ }^{\ddagger}$ & $97.2 \pm 1.1$ & $98.3 \pm 1.7$ & $92.3 \pm 1.2$ & $93.4 \pm 1.8$ & $83.6 \pm 2.0$ & $89.6 \pm 0.9$ & $56.4 \pm 1.7$ & $88.2 \pm 0.8$ & $42.5 \pm 2.7$ & $81.6 \pm 1.8$ \\
\hline
\end{tabular}

Results represent mean percentage \pm SD of IIF-positive cells (in duplicate), $20 \mathrm{~h}$ after UVB irradiation. ${ }^{*}$ As detailed in Table I, patient 10. * Immediately before cell fixation (viability II). No difference in cell viability was observed ampng cells of same source incubated with the different probes at any given dose of UVB irradiation. 


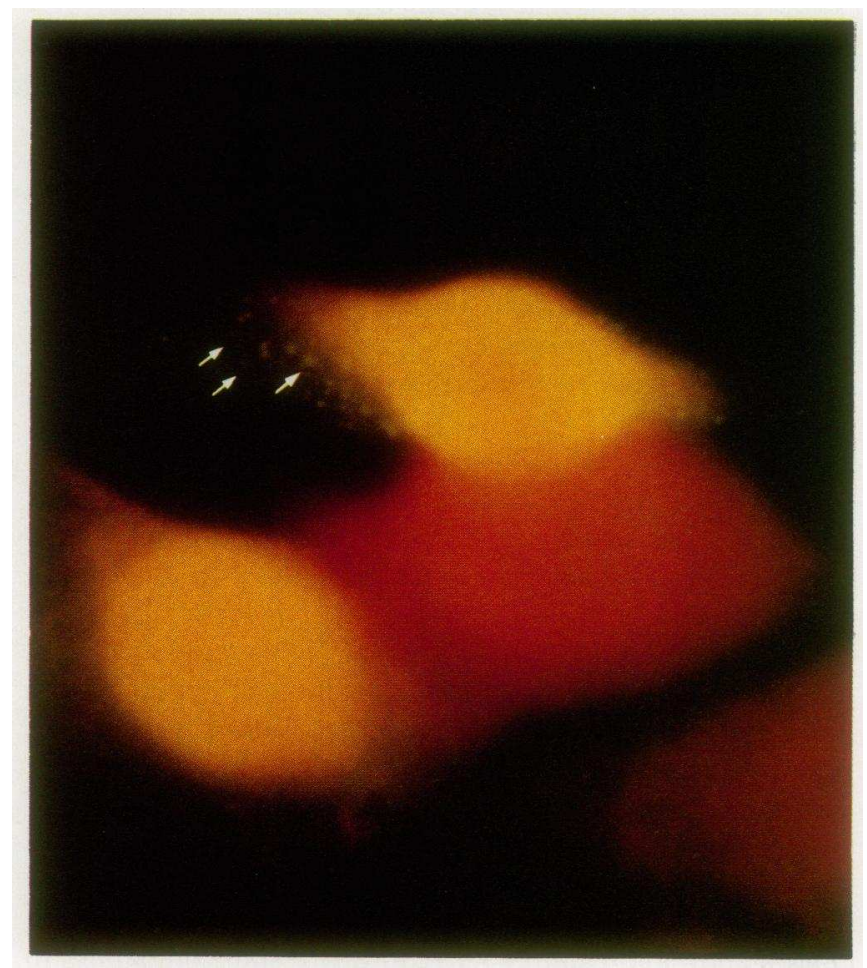

Figure 4. IIF staining of SLE-derived nonirradiated keratinocytes by autologous serum. Magnification, 550. Technical details similar to Fig. $1 \mathrm{~A}$. Cell source: patient 10 . Note punctate cell membrane, cytoplasmic (arrows) or nuclear staining of cells in the microscopic field. No cells in this field were stained with TB.

diation has been previously described, we reasoned that skinderived cells from such patients may express these cell surface antigens more readily. We therefore investigated the expression of soluble (SSA, SSB, Sm, RNP) and relatively fixed (dsDNA) intracellular antigens on the cell surface of SLE patients' keratinocytes (in remission or with mild clinical activity to exclude biased results provoked by medications), in nonexposed and UV-exposed specimens in vitro. We examined whether nonirradiated SLE-derived cells differ from normal cells and whether an enhanced expression may be elicited by low dose UVB exposure in which normal cells were minimally affected. Our study is the first to show that the majority of SLE patients studied demonstrate an enhanced and selective expression of soluble intracellular antigens on the keratinocyte cell membrane after $200 \mathrm{~J} / \mathrm{m}^{2}\left(=20 \mathrm{~mJ} / \mathrm{cm}^{2}\right)$ UVB irradiation in vitro. Such an exposure to the skin surface could be achieved in as little as $10 \mathrm{~min}$ in midday sun, although somewhat less energy may penetrate to the deeper epidermal layers due to scattering. This antigen expression is believed to be mainly a UVB-evoked response, since deliberate contamination of the UVB source with a 25-fold excess of UVA did not further increase antigen expression. As trace quantities of UVA could not be totally eliminated from the UVB source, we cannot absolutely exclude a combined UVA/UVB effect. Moreover, in some patients' strains, an increased detection of these antigens was present in nonirradiated cells, perhaps elicited by ambient UVR (16).

As reported by LeFeber et al. (13), a very small percentage of normal unfixed cells stained positively with the autoantibody probes (Table II). However, the UVB dose required to induce cell surface antigen expression $(13,14)$ was somewhat higher than that reported here. These differences may be related to differences in staining methodology, cell origins, or titer of the antibody probes used for detection. The observation of increased autoantibody binding to normal cells (14) was obtained after exposure of the cells to a high dose of UVB (an equivalent of $\geq 30$ minimal erythema dose in vivo). In contrast, our current report demonstrated increased autoantibody binding even in nonirradiated cells of some SLE strains, and the remainder showed an increased sensitivity after being exposed to a low dose of UVB (Fig. 2).

The underlying mechanism(s) accountable for enhanced and selective expression of SCAs on the cell membrane of SLEderived UV-irradiated keratinocytes was not directly addressed in this study. Previous observations by others in normal-derived UV-irradiated keratinocytes showed that the presence of these antigens on the cell membrane was occurring selectively in injured but still metabolic active cells (13). The possibility was raised that such an expression was due to passive leakage of antigen in dying cells, but it was considered unlikely since it was observed in cells without otherwise altered membrane permeability and required active protein synthesis (13). In addition, glycosylation, glycolysis, and intact microfilament function were proven requirements of this metabolic process (14). The lack of cell membrane or intracellular positive IIF staining of TB-negative keratinocytes when anti-GT (membrane-anchored protein in endoplasmic reticulum) was used as primary antibody further demonstrated the selectivity of the process. Our results and those of previous studies are most consistent with the notion that UVR may produce cellular membrane damage that allows some soluble or diffusable cellular antigens to become inappropriately expressed on the external cell surface.

The significantly decreased viability of low-dose UVB-irradiated SLE cells observed in the present study (Fig. 3) might be due to a primary deficient DNA repair mechanism in SLE-derived cells $(16,21-24)$ with secondary effects on RNA and protein synthesis or to concomitant damaging effects of reactive oxygen species induced by UVR on targets, such as cell membrane, cytoskeleton, mitochondria, and enzymatic processes (25). The kinetics of enhanced SCA expression on SLE cell membrane, which is demonstrated best $18-20 \mathrm{~h}$ after UV irradiation, is in favor of the former, being supported by the findings in DNA repair-deficient xeroderma pigmentosumderived cells, in which it was demonstrated that UV effect on RNA synthesis was caused by UV-induced DNA lesions, which further led to delayed effect on protein synthesis, best observed 15-30 h after irradiation (26). Whether enhanced SCA presence on the cell surface results from UV-induced neoantigen expression or whether it may serve as an independent marker of diffusable antigens in severely damaged cells needs further clarification.

A potential problem exists when whole sera or globulin fractions are used as autoantibody-binding probes, namely, that cross-reacting antibodies or antibodies not detected by current methods might be responsible for the IgG binding to cell surface of keratinocytes. Although we used autoantibody probes that were studied in detail previously $(18,19)$, we cannot exclude the possibility that these sera also contained antibodies that bound to other antigens or to neoantigens created by UV irradiation. In some experiments in which autologous 
serum was used, strong binding to self-derived keratinocytes of SLE origin was observed (Table IV). Whether these antigens are keratinocyte-specific is under further investigation.

Another observation of interest was the increased extracellular presence of intracellular material in 3 out of $12 \mathrm{UV}$-unexposed keratinocyte strains and in all of $10 \mathrm{UV}$-susceptible SLE strains after exposure to low dose UVB (Fig. 2). These findings, as well as those described above, may have bearing on the unresolved debate regarding the formation of the lupus band, which is present in both the damaged and apparently healthy skin of SLE patients $(5,27,28)$. This linear band at the dermoepidermal junction is thought by some investigators to be the result of deposition of immune complexes formed in circulation, whereas others have suggested that they are produced locally in the areas of UV-damaged skin $(6,8,29-31)$. Our earlier in vitro studies, demonstrating increased spontaneous and UV-induced release of DNA from lymphocytes of SLE patients and animal models $(10,32,33)$, and our current report, showing that 10 out of 12 UV-irradiated SLE keratinocyte strains have decreased cell viability and increased expression of intracellular antigens on the cell membrane, support the notion of in situ formation of these immune complexes. Furthermore, it can be speculated that excess cellular material, released from UV-injured keratinocytes after exposure in vivo, may escape the local process of "trapping" at the basement membrane of the dermo-epidermal junction. Thus, the antigenic overflow beyond the skin barrier could form immune complexes in the circulation and reach other organs (34).

Demonstration of increased sensitivity of SLE keratinocytes to UVB irradiation with increased expression of lupus-related antigens after ultraviolet light exposure has several important clinical implications. First, increased expression of lupus-related antigens at the cell surface or in the extracellular space could provide an initial antigenic challenge for development of specific autoantibodies. Second, in situ formation of antigen-autoantibody complexes within the skin could activate complement or other proinflamatory pathways within the skin, resulting in erythema and other clinical signs of the photodermatitis associated with cutaneous lupus erythematosus. Basal keratinocyte vacuolization, basement membrane thickening, periappendageal fibrosis, and chronic inflammatory cell infiltrates in affected skin could all result from prolonged inflammation triggered by in situ antigen-antibody formation or local $\mathrm{T}$ cell activation at sites of antigenic release. Third, the clinical appearance of a typical solar-induced skin rash may be due to a variety of variables including degree of sun exposure, use of photoprotective agents, circulating titers of specific lupus antibodies, variable formation of autoantibodies specific for epidermal antigens, and expression of UV-induced antigens at different epidermal levels and/or their ability to diffuse into extracellular or basement membrane regions.

\section{Acknowledgments}

We thank Dr. Charles Christian and Dr. D. Martin Carter for their help and support, Ina Leong for excellent technical assistance, Dr. Andrew N. Lin and Dr. Val Pierre Vallat for obtaining skin specimens, and Dr. Margaret Peterson for statistical analysis of data. We also thank the following students of Cornell University Medical College: Joanna Preibisz, David Schulman, and Lucia Boselli, who helped to recruit patients for this study.
This research was supported by research grants from the National Institutes of Health PHS-AR-38520, AR-38915, and a General Clinical Research Grant from the National Institutes of Health to the Rockefeller University Hospital (M01-RR00102); by The Skin Disease Society, New York; and with general support from the Pew Trusts. T. D. Golan was supported by a scholarship grant from the Ministry of Health, State of Israel, and by grants from the Terri Gotthelf Lupus Research Institute and the Ridgefield Foundation.

\section{References}

1. Tan, E. M., A. S. Cohen, J. P. Fries, A. T. Masi, D. J. McShane, N. F. Rothfield, J. G. Schaller, N. Talal, and R. J. Winchester. 1982. The 1982 revised criteria for the classification of systemic lupus erythematosus. Arthritis Rheum. 25:1271-1277.

2. Epstein, J. H., D. L. Tufanelli, and E. L. Dubois. 1985. Light sensitivity and lupus erythematosus. Arch. Dermatol. 91:483-485.

3. Freeman, R. G., J. M. Knox, and D. W. Owen. 1969. Cutaneous lesions of lupus erythematosus induced by monochromatic light. Arch. Dermatol. 100:677682 .

4. Lehmann, P., E. Hölzle, P. Kind, G. Goerz, and G. Plewig. 1990. Experimental reproduction of skin lesions in lupus erythematosus by UVA and UVB radiation. J. Am. Acad. Dermatol. 22:181-187.

5. Zamansky, G. B. 1985. Sunlight-induced pathogenesis in systemic lupus erythematosus. J. Invest. Dermatol. 85:179-180.

6. Provost, T. T. 1981. The lupus band test. Int. J. Dermatol. 20:475-481.

7. Cripps, D. J., and J. Rankin. 1973. Action spectrum of lupus erythematosus and experimental immunofluorescence. Arch. Dermatol. 107:563-567.

8. Natali, P. G., and E. M. Tan. 1973. Experimental skin lesions in mice resembling systemic lupus erythematosus. Arthritis Rheum. 16:579-589.

9. Tan, E. M., and R. R. Stoughton. 1969. Ultraviolet light alteration of cellular DNA in vivo. Proc. Natl. Acad. Sci. USA. 62:708-714.

10. Golan, T. D., and Y. Borel. 1984. Increased sensitivity to near-UV light in murine SLE. J. Immunol. 132:705-710.

11. Smith, K. C. 1978. Molecular aspects of the interaction of far-UV radiation with living matter. In International Symposium on Current Topics in Radiobiology and Photobiology. R. M. Tyrrell, editor. Rio de Janeiro. 61 .

12. Parrish, J. A., R. R. Anderson, F. Urbach, and D. Pitts. 1978. Effect of ultraviolet radiation on microorganisms and animals cells. In UV-A: Biological Effects of Ultraviolet Radiation with Emphasis on Human Response to Longwave Ultraviolet. J. A. Parrish, R. R. Anderson, F. Urbach, and D. Pitts, editors. Plenum, New York. 85-106.

13. LeFeber, W. P., D. A. Norris, S. S. Ryan, J. C. Huff, M. Kubo, S. T. Boyce, B. L. Kotzin, and W. L. Weston. 1984. Ultraviolet light induces expression of selected nuclear antigens on cultured human keratinocytes. J. Clin. Invest. 74:1545-1551.

14. Furukawa, F., M. Kashihara-Sawami, M. B. Lyons, and D. A. Norris. 1990. Binding of antibodies to the extractable nuclear antigens SS-A/Ro and SS-B/La is induced on the surface of human keratinocytes by ultraviolet light: implications for the pathogenesis of photosensitive cutaneous lupus. $J$. Invest. Dermatol. 94:77-85.

15. Sontheimer, R. D., P. J. Maddison, M. Reichlin, R. E. Jordon, P. Stasyny, and J. N. Gilliam. 1982. Serologic and HLA associations in subacute cutaneous lupus erythematosus, a clinical subset of lupus erythematosus. Ann. Intern. Med. 97:664-671.

16. Golan, T. D., V. Foltyn, and A. Roueff. 1991. Increased susceptibility to in vitro ultraviolet B radiation in fibroblasts and lymphocytes cultured from systemic lupus erythematosus patients. Clin. Immunol. Immunopathol. 58:289304.

17. Kiistala, U., and K. K. Mustakallio. 1967. Dermoepidermal separation with suction. Electron microscopic and histochemical study of initial events of blistering of human skin. J. Invest. Dermatol. 48:466-477.

18. Elkon, K. B., and L. Culhane. 1984. Partial immunochemical characterization of the Ro and La proteins, using antibodies from patients with the sicea syndrome and lupus erythematosus. J. Immunol. 132:2350-2356.

19. Elkon, K. B., and P. Jankowski. 1985. Fine specificities of autoantibodies directed against the Ro, La, Sm, RNP and Jo-1 proteins defined by two-dimensional gel electrophoresis and immunoblotting. J. Immunol. 134:3819-3824.

20. Parks, D. R., W. M. Bryan, V. T. Oi, and L. A. Herzenberg. 1979. Antigen specific identification and cloning of hybridomas with fluorescence-activated cell sorter (FACS). Proc. Natl. Acad. Sci. USA. 76:1962-1965.

21. Beihglie, D. J., and R. L. Teplitz. 1975. Repair of UV-damaged DNA in systemic lupus erythematosus. J. Rheumatol. 2:149-160.

22. Harris, G., L. Asbery, P. D. Lawley, A. M. Denman, and W. Hylton. 1982. Defective repair of $\mathrm{O}^{6}$-methyguanine in autoimmune disease. Lancet. ii:952956. 
23. Takeuchi, F., F. Otsuka, T. Enomoto, F. Hanaoka, M. Yamada, N. Kamatani, K. Nakano, K. Matsuta, K. Tanimoto, T. Morita, et al. 1985. Decrease in the reaction of DNA repair synthesis in response to nicotinamide or 3-aminobenzamide in ultraviolet irradiated systemic lupus erythematosus lymphocytes. $J$. Rheumatol. 12:504-507.

24. Blount, S., H. R. Griffiths, and J. Lunec. 1991. Reactive oxygen species damage to DNA and its role in systemic lupus erythematosus. Mol. Aspects Med. 12:99-105.

25. Cochrane, C. G. 1991. Mechanisms of oxidant injury of cells. Mol. Aspects Med. 12:137-147.

26. Kantor, G. J., and D. R. Hull. 1979. An effect of ultraviolet light on RNA and protein synthesis in nondividing human diploid fibroblasts. Biophys. $J$. 27:359-370.

27. Burnhan, T. K., T. R. Neblett, and G. Fine. 1963. The application of the fluorescent antibody technique to the investigation of lupus erythematosus and various dermatoses. J. Invest. Dermatol. 41:451-456.

28. Cormane, R. H. 1964. "Bound" globulin in the skin of patients with chronic DLE and SLE. Lancet. i:534-535.
29. Gilliam, J. N. 1975. The significance of cutaneous immunoglobulin deposits in lupus erythematosus and $(\mathrm{NZB} / \mathrm{NZW}) \mathrm{F}_{1}$ hybrid mice. J. Invest. Dermatol. 65:154-161.

30. Davis, P., and J. S. Percy. 1978. Role of ultraviolet light and UV-DNA in the induction of skin lesions in experimental animals. Br. J. Dermatol. 99:201205.

31. Beisecker, G., L. Lavin, M. Ziskind, and D. Koffler. 1982. Cutaneous localization of the membrane attack complex in discoid and systemic lupus erythematosus. N. Engl. J. Med. 306:264-270.

32. Golan, T. D., J. Mossel, V. Wolf, R. Sharon, and R. Ben-Ishai. 1980. DNA synthesis release and repair in systemic and discoid lupus erythematosus patients. Isr. J. Med. Sci. 16:802. (Abstr.)

33. Golan, T. D., and Y. Borel. 1983. Spontaneous increase of DNA turnover in murine systemic lupus erythematosus. Eur. J. Immunol. 13:430-433.

34. Decker, J. L., A. D. Steinberg, J. L. Reinertsen, P. H. Plotz, J. E. Balow, and J. H. Klippel. 1979. Systemic lupus erythematosus: evolving concepts. Ann. Intern. Med. 91:587-604. 